\title{
3D Modeling for Rock Art Documentation using Lightweight Multispectral Camera
}

\author{
K. Zainuddin ${ }^{1,2}$, Z. Majid ${ }^{2}$, M. F. M. Ariff ${ }^{2}$, K. M. Idris ${ }^{2}$, M.A. Abbas ${ }^{1}$, N. Darwin ${ }^{2}$ \\ ${ }^{1}$ Center of Study for Surveying Science \& Geomatics, Faculty of Architecture, Planning \& Surveying Universiti Teknologi MARA, \\ MALAYSIA -khairul760@ perlis.uitm.edu.my, mohdazwanabbas@gmail.com \\ ${ }^{2}$ Geospatial Imaging and Information Research Group, Universiti Teknologi Malaysia, MALAYSIA - (zulkeplimajid, mfaridma, \\ khairulnizami, norhadija2) @utm.my
}

\section{Commission II}

KEY WORDS: Rock Art, Geometric Recording, Multispectral Camera, TLS, SfM.

\begin{abstract}
:
This paper discusses the use of the lightweight multispectral camera to acquire three-dimensional data for rock art documentation application. The camera consists of five discrete bands, used for taking the motifs of the rock art paintings on a big structure of a cave based on the close-range photogrammetry technique. The captured images then processed using commercial structure-from-motion photogrammetry software, which automatically extracts the tie point. The extracted tie points were then used as input to generate a dense point cloud based on the multi-view stereo (MVS) and produced the multispectral 3D model, and orthophotos in a different wavelength. For comparison, the paintings and the wall surface also observed by using terrestrial laser scanner which capable of recording thousands of points in a short period of time with high accuracy. The cloud-to-cloud comparison between multispectral and TLS 3D point cloud show a sub-cm discrepancy, considering the used of the natural features as control target during 3D construction. Nevertheless, the processing also provides photorealistic orthophoto, indicates the advantages of the multispectral camera in generating dense 3D point cloud as TLS, photorealistic 3D model as RGB optic camera, and also with the multiwavelength output.
\end{abstract}

\section{INTRODUCTION}

Rock art is a historical heritage, consisting of pictographs and petroglyphs, painted or engraved thousands of years ago by prehistoric peoples. Since the paintings have been existing for an extended period, the pictographs have facing the degradation process due to natural factors such as weather, animals, microorganisms, as well as a risk due to the vandalism by humans (Bendicho et al., 2017; Domingo et al., 2013). Rock art considered as fragile natural heritage object, as it having progress degradation due to the factors mentioned, thus documenting the motifs into digital form is essential for future reference, research, and dissemination (Bendicho et al., 2017; Domingo et al., 2013).

Documenting the precise rock art geometry is increasingly demanding in cultural heritage (Georgopoulos \& Stathopoulou, 2017). Various techniques are available to record the geometry of the paintings such as direct tracing and rubbing (Brayer et al., 1998; Delporte, 1994), photography (Domingo et al., 2015), laser scanning (Lerma et al., 2014) and photogrammetry (Lerma \& Muir, 2014). Tracing and rubbing are the classical methods widely used to document the geometry of the motifs, but the method having a risk on damaging the paintings due to the pressure applied during documentation work. Furthermore, the recording techniques are also having the distortion problem (López-Montalvo \& Sanz, 2005), where the traced of the irregular surface transformed into two-dimensional plain media. When the documentation project involving large motifs, then storing into manageable scales also problematic (Sanz, 2014).

The photography method in the other hand reduced the damaging effect during the data collection process by tracing the motifs digitally. The captured images from the digital camera can be transferred into the imaging software for enhancement and scales into any size required since the image stored in a digital format (Domingo et al., 2015). However, the photographic task usually produced distorted imagery, therefore, to reduce the distortion effect, the camera's optical axes placed orthogonally as possible to the motifs during data acquisition (Domingo et al., 2013).

Documentation by the digital three-dimensional (3D) model is well known when the actual metric dimension is taken into consideration (Georgopoulos \& Stathopoulou, 2017). The 3D data can be acquiring either base on the range-based or imagebased modeling. Regarding range-based modeling, terrestrial laser scanner (TLS) capable to observe and record thousands of points in a short period and the produced high accurate point cloud. However, the device usually not preferable for data acquisition tools among archaeologist due to the budget constraint (Beraldin et al., 2011). Even though the instruments getting smaller and handy to transport into the remote rock art site not like before, but the price of the tools still become the main limitation (Bendicho et al., 2017). Moreover, to use the TLS usually required well-trained and skilled personnel, while for data acquisition in the field of rock art usually employ the volunteers.

In contrast, image-based modeling by photogrammetry provides a more affordable solution in generating $3 \mathrm{D}$ point cloud as similar to TLS but derives from the imagery and the mathematical model. Current photogrammetry technique which combined with computer vision (CV) algorithm, known as structure-frommotion (SfM) and multi-view stereo (MVS) capable of generating the 3D model and orthophoto automatically. With SfM, the tie point automatically detected using SURF (Lowe, 2004) or SIFT (Bay et al., 2008) from image pair and generating the sparse point cloud. The input from the SfM then uses to generate the dense point cloud using MVS for further output such as photorealistic 3D model and orthophoto (Barazzetti et al., 2012).

However, regarding rock art documentation problem which facing deterioration process, the paintings getting blur and faded. Moreover, in some cases, the precise geometry of the paintings 
are hardly to identify due to the superimposition layer between pictographs. Therefore, using the photorealistic 3D model and orthophoto are insufficient to detect the faded paintings as well as distinguish overlapped drawings (Sanz, 2014). Nevertheless, the tool such as NIR cameras (Fredlund \& Sundstrom, 2007) is often used to record the invisible features of the objects. Moreover, the multispectral cameras are used in rock art documentation due to the advantages of recording spectral responses (Del Pozo et al., 2017) as an enhancement to NIR cameras, enable the analysis such as correct color analysis (Bianco et al., 2011), pigment classification (Cosentino, 2015), and distinguish between the over-painted layer of pigments (Skoog et al., 2016). The modification of standard color digital camera into full spectrum camera provides capability of capturing a variety of imagery in a different wavelength by utilizing a wide range of bandpass filters up to $1200 \mathrm{~nm}$ (Verhoeven, 2016). However, the modification process is not an easy task because it requires a dust-free environment and specialized skill. Otherwise, any error will harm the camera system (Verhoeven, 2016). Moreover, using the single lens multispectral camera requires the focus to be set depending on the bandpass filter due to changes on principal distance with the wavelength (Robson et al., 2014) and takes a long time for observation at the site (Pamart et al., 2017).

Nowadays, the state-of-the-art multispectral cameras which is small and lightweight are available in the market, designed to be mount on the UAV for agriculture purpose. Not limited to the UAV platform, the miniature multispectral cameras also can be exploited as a close-range photogrammetry tool. The acquired imageries from the camera later can be processed using SfM photogrammetry tool to generate the 3D model and orthophoto. The output from the processing then can use for geometric documentation based on the multispectral layers, which can be analyzed base on different wavelengths. Thus, this paper aims to evaluate the potential of using the lightweight multispectral camera for rock art geometric documentation using SfM photogrammetry.

In this paper, the multispectral camera was used to capture the rock art motifs on the wide rock shelter at the Gua Tambun. Located at Ipoh town, Perak, Gua Tambun is a largest rock art site at Peninsular Malaysia having a great size of pictographs in different form and color on the main panel (Tan \& Chia, 2012). The main panel (Figure 1) is about $10 \mathrm{~m}$ wide and $4 \mathrm{~m}$ high, located about $6 \mathrm{~m}$ from the cave floor, which has an altitude of $50 \mathrm{~m}$ from the ground (Tan \& Chia, 2012).

\section{3D MODELING BY MULTISPECTRAL CAMERA}

\subsection{Camera Specifications}

In this project, the Micasense RedEdge multispectral camera (Figure 2) was used to capture the rock art painting of Gua Tambun. The multispectral camera contained five discrete CMOS sensors allows to capture narrowband wavelength (Table 1). For every single capture generates a set of five images of mentioned wavelength for the same scene. The camera was calibrated using photogrammetric self-calibration bundle adjustment technique for metric modeling.

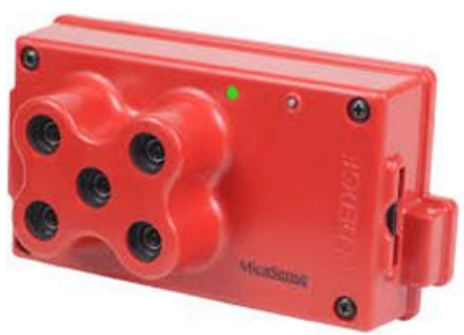

Figure 2: Micasense RedEdge multispectral camera.

Table 1. RedEdge multispectral specifications.

\begin{tabular}{|c|c|c|}
\hline $\begin{array}{c}\text { Calibrated Focal } \\
\text { Length }(\mathrm{mm})\end{array}$ & \multicolumn{2}{|c|}{$5.4150 \sim 5.4544$} \\
\hline Sensor Size $(\mathrm{mm})$ & \multicolumn{2}{|c|}{$4.8 \times 3.6$} \\
\hline Resolution (pixels) & \multicolumn{2}{|c|}{$1280 \times 960$} \\
\hline Pixel size $(\mu \mathrm{m})$ & \multicolumn{2}{|c|}{3.75} \\
\hline Weight $(\mathrm{g})$ & \multicolumn{2}{|c|}{150} \\
\hline Dimension $(\mathrm{cm})$ & $12.1 \times 6.6 \times 4.6$ \\
\hline Band & $\begin{array}{c}\text { Centre } \\
\text { Wavelength }(\mathrm{nm})\end{array}$ & $\begin{array}{c}\text { Bandwidth } \\
(\mathrm{nm})\end{array}$ \\
\hline Blue & 475 & 20 \\
\hline Green & 560 & 20 \\
\hline Red & 668 & 10 \\
\hline Red-edge & 717 & 40 \\
\hline $\begin{array}{c}\text { Near-infrared } \\
\text { (NIR) }\end{array}$ & 840 & 10 \\
\hline
\end{tabular}
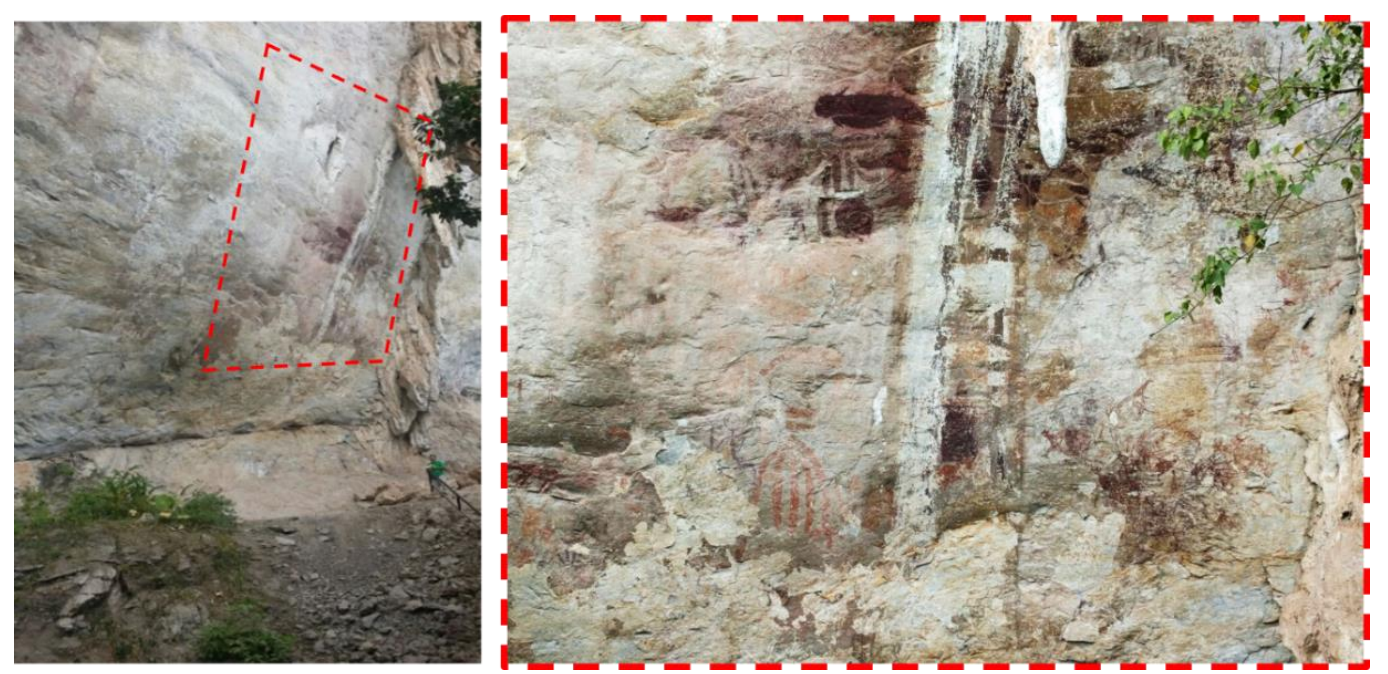

Figure 1: The main panel of the rock art at Gua Tambun. The dashed red box shows the location of the motifs. 


\subsection{Close-range photogrammetry data acquisition using the multispectral camera}

The camera was set on the tripod and placed in arbitrary position, about $10 \mathrm{~m}$ from the wall for data capture. Since the camera manufactured without a viewfinder on the camera's body for aiming the object, thus the image was viewed through the camera's web interface, which requires Wi-Fi connection between the camera and tablet for communication. The camera web interface also provided virtual trigger button to allow the manual image capture. The images acquired about $85 \%$ overlap with three different height setting to ensure a good 3D reconstruction. The data collection only focused on the main panel area which has containing few numbers of the painting for documentation.

There was also GNSS connection problem at the site, caused by the massive structure of the cave (about $50 \mathrm{~m}$ height from ground level) blocking the signal to receive by the camera's GPS module. Therefore, no georeferenced information tagged into the image for alignment processing. Moreover, no any marker allowed to be put into the wall surface for the control point. Therefore, as this project to evaluate the capability of lightweight multispectral for 3D documentation, control points were extracted from TLS point cloud for datum definition. The selected points consisted of decent texture to ensure it can be detected and located on the multispectral imagery. Overall, ten points selected for scaling and orientation of the model, which six points were used as control targets while the rest of four points utilized as checkpoints.

\subsection{Multispectral image processing for geometric modeling}

Agisoft PhotoScan were used to reconstruct the multispectral imagery into the 3D model in this study. Before the processing begins, each image was inspected for the blur and poor quality to make sure it does not use for processing. A few sets of images were filtered out and keep the suitable images with good quality and overlap, which only 53 out of 85 set were used for 3D reconstruction. PhotoScan capable of processing multispectral imagery by selecting any processing band as the primary channel for generating 3D point cloud during processing. When using the default selection set by the software, PhotoScan generates a color point cloud, by taking the visible band into processing. However, if any band choose for primary channel processing, e.g., the green band, then a monochrome 3D model based on green channel displays on the processing area. This paper was used default selection for point cloud reconstruction and generated a set of multi-layers 3D model and orthophoto.

The pre-calibrated camera parameters based on photogrammetric self-calibration bundle adjustment technique were used to ensure the correct interior parameter and camera orientation computed during the photogrammetric processing (Luhmann et al., 2016; Remondino \& Fraser, 2006). The generated tie point examined and filtered out the error based on the image count, reprojection error, reconstruction uncertainty and projection accuracy (James et al., 2017) to improve the accuracy of the final model. The adjusted sparse point cloud then used as input for detail dense point cloud by using multi-view stereo method. The dense point cloud later exploited for multispectral 3D modeling and orthophotos generation. As aforementioned, PhotoScan generated multi-layer orthophotos, thus, to export a single channel orthophoto for spectral analysis can be realized by raster calculator tool.

\section{DATA ACQUISITION AND 3D MODELING BY TLS}

Regarding 3D modeling by TLS, the Faro Focus 3D (Figure 3) was used by placing the device and sphere targets at strategic locations during data acquisition. The measurement set to medium resolution for manageable point cloud output used for processing using Faro Scene software. The sphere targets used to register the point cloud from three different scanning station on Faro Scene. The generated point cloud then integrated with images information from the built-in Red-Green-Blue (RGB) camera to produce color point cloud and useful for visualization.

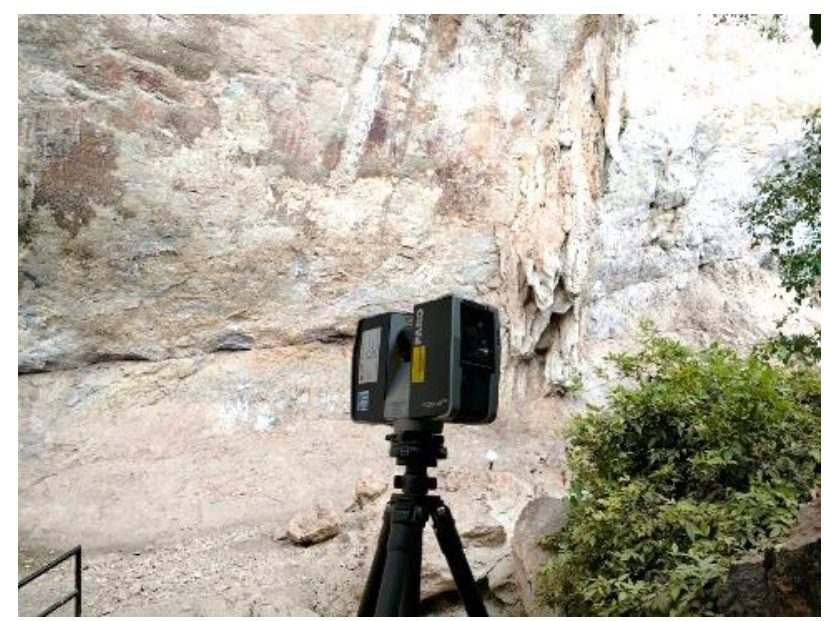

Figure 3: The Faro Focus 3D TLS used in the study.

\section{EXPERIMENTAL RESULTS}

Based on the SfM processing, 64,376 cleaned sparse point cloud used to reconstruct $3 \mathrm{D}$ dense point cloud contained a total of $4,748,512$ points with RMS of $0.292 \mathrm{~m}$ ( 0.494 pixels), obtained (Figure 4). Considering the natural features employed to mark the control point from TLS data into the multispectral point cloud, some of the points were not precisely located, with the maximum error was at GCP11 $(0.039 \mathrm{~m})$ and total RMSE of control and checkpoints gained $2.282 \mathrm{~cm}$ and $2.463 \mathrm{~cm}$, respectively.

The reconstructed multispectral 3D dense point cloud then saved into *.laz format and exported to CloudCompare for analysis. Data of multispectral were aligned to TLS point cloud using Iterative Closest Point (ICP) algorithm, with 5 million points in random sampling limit to ensure all the multispectral point cloud counts for alignment.

Based on Figure 5, the final RMS for alignment yields $0.015 \mathrm{~m}$. Most of the compared area shows good correspondence with mean distance error $0.008 \mathrm{~m}$ and standard deviation of $0.013 \mathrm{~m}$. The comparison achieved the result of distance discrepancies $<0.016 \mathrm{~m}$ at a $95 \%$ confidence interval. The substantial error observed in the multispectral point cloud caused by weak overlap which has a small number of projected points during 3D construction especially at the edge area of the model shown by the white and red color. Moreover, the discrepancies arise at the outside of the control point area indicates the importance of the control frame on the modeling process. 


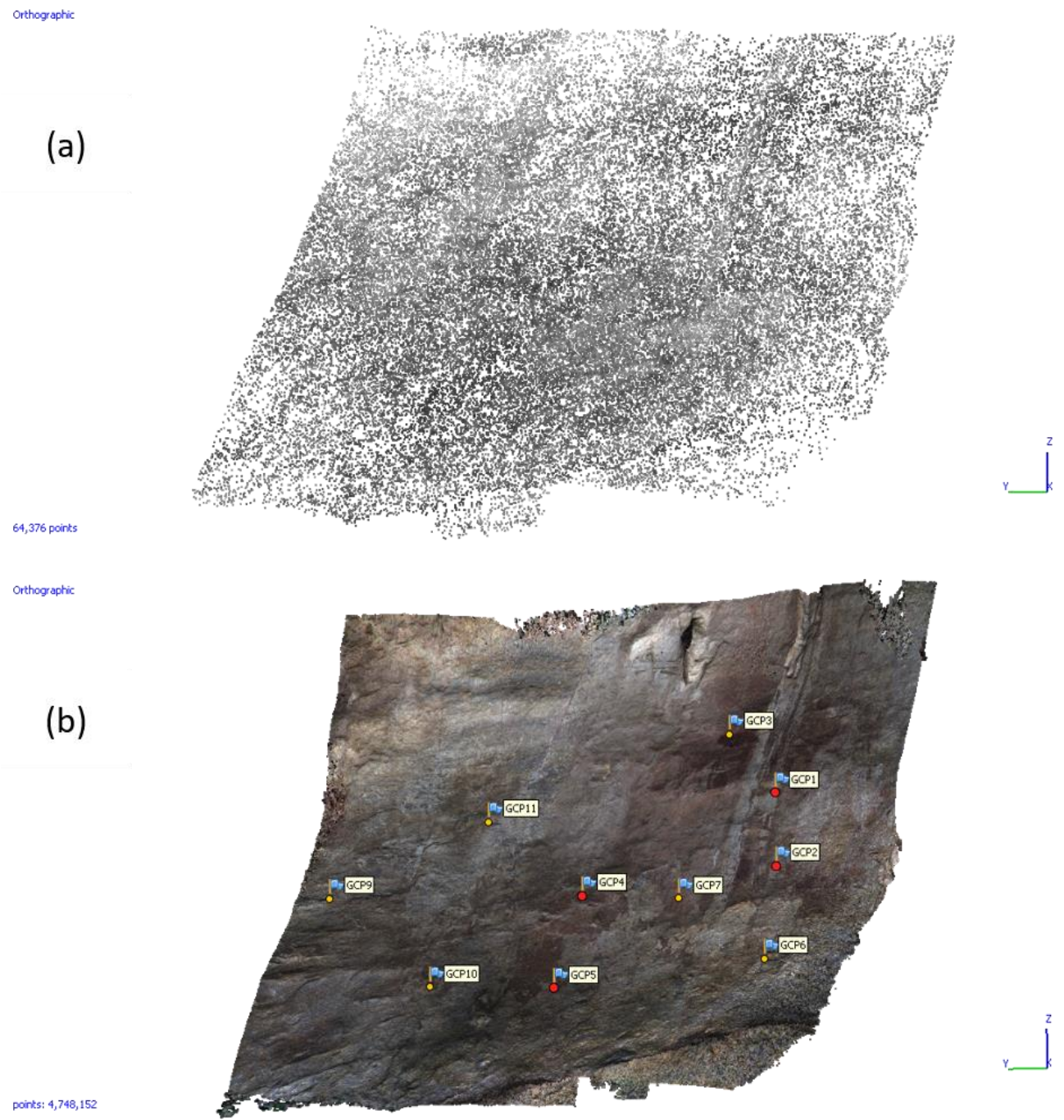

Figure 4: Point cloud reconstruction from SfM: (a) cleaned sparse point cloud, and (b) 3D dense point cloud of multispectral imagery based on default channel selection in PhotoScan with the distribution of control point (yellow point flag) and checkpoint (red point flag).

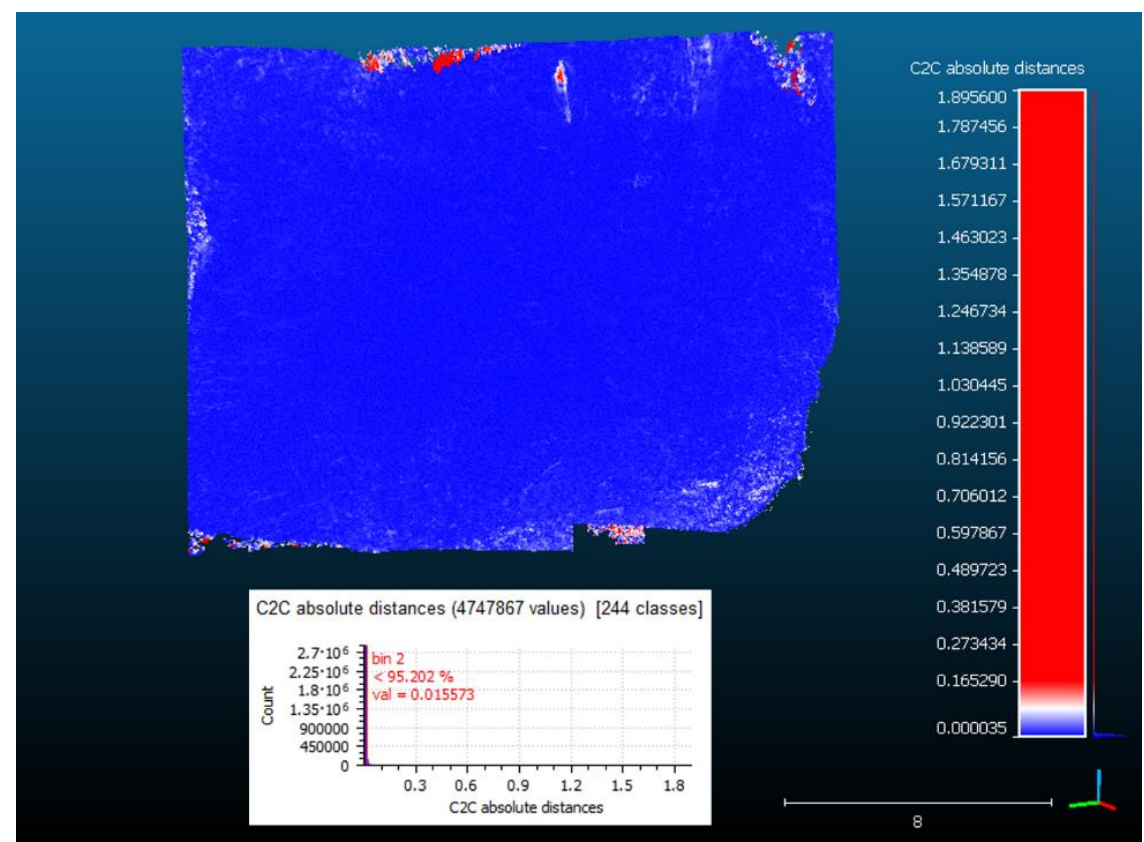

Figure 5: Cloud-to-cloud distance comparison between multispectral and TLS data. 


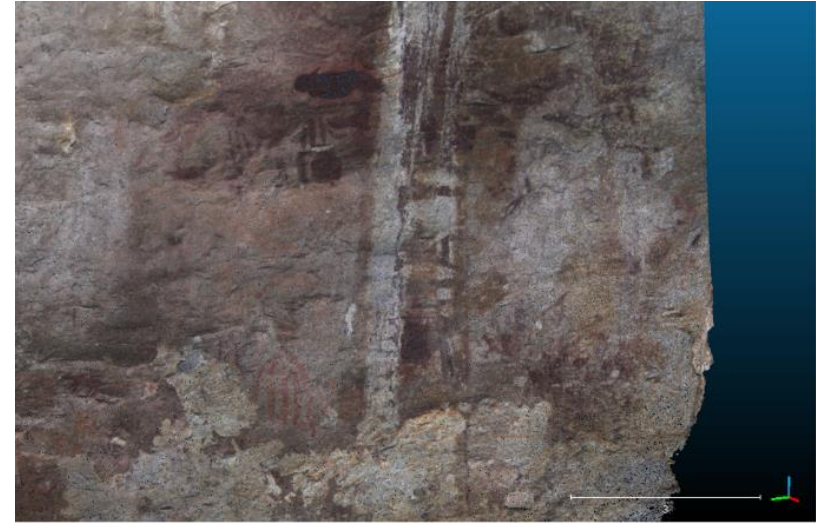

(a)

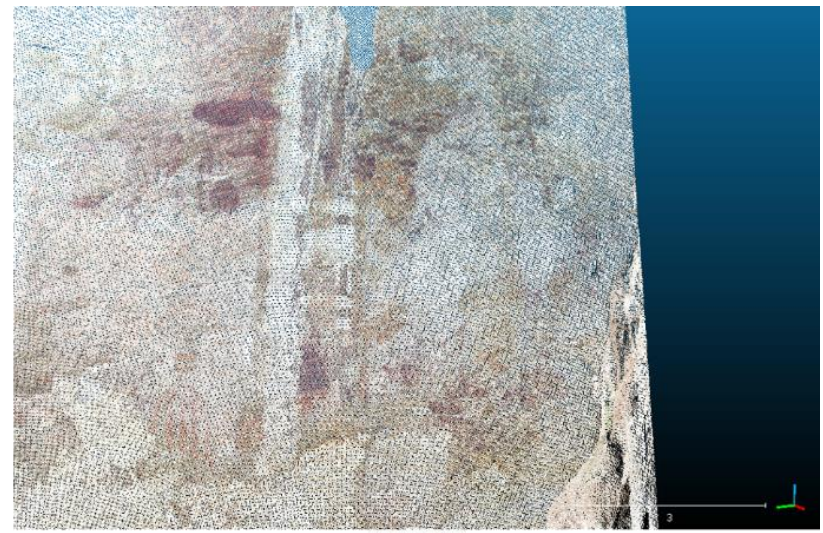

(b)

Figure 6: The visual comparison of color point cloud from (a) multispectral, and (b) terrestrial laser scanner.

Figure 6 shows the comparison between multispectral and terrestrial point cloud as the visual quality level. The output from multispectral gives clearer visual on rendered color compared to terrestrial laser scanning. Regarding multispectral, the point cloud was generated based on image-based technique, which has good sensor resolution of about $8 \mathrm{~mm}$ GSD from $10 \mathrm{~m}$ observation. While for TLS which uses range technique, the weak visual on point cloud was due to the limitation of the resolution and scanning angle of scanner's built-in camera.

Besides generate the photorealistic orthophoto, the advantage of multispectral imagery is capable of visualizing and documenting the rock art painting based on the different bands. In this paper, the rock art painting documented in five different bands. As shown in Figure 7, the close-up view paintings on dancing man were visible on all bands as the drawing made by charcoal. Meanwhile, the abstract octopus-like drawing is appearing on $475 \mathrm{~nm}$ and $560 \mathrm{~nm}$, but not responses from $668 \mathrm{~nm}$. Therefore, the multispectral orthophoto can be exploited to distinguish the overlayer painting, and precise geometric extraction of the motifs can be done on orthophoto overlaid with DEM. Moreover, the spectral information can be used to analyze the correct color and the type of the pigment used in rock art painting at Gua Tambun, but it is out of scope in this paper.

\section{CONCLUSION}

This paper highlights the $3 \mathrm{D}$ modeling from the lightweight multispectral camera based on SfM Photogrammetry processing. As a visual assessment, the point cloud of multispectral shows better color details compared to the TLS point cloud. By generating a multispectral orthophoto, the 3D model can be visualized not limited to visible bands but can be configured to invisible channels, depending on the number of sensors built on the camera system. Moreover, the generated multispectral orthophoto also can be used for analysis image processing technique for rock art documentation, e.g., Principal Component Analysis (PCA) and decorrelation stretch (Cerrillo-cuenca \& Sepúlveda, 2015).

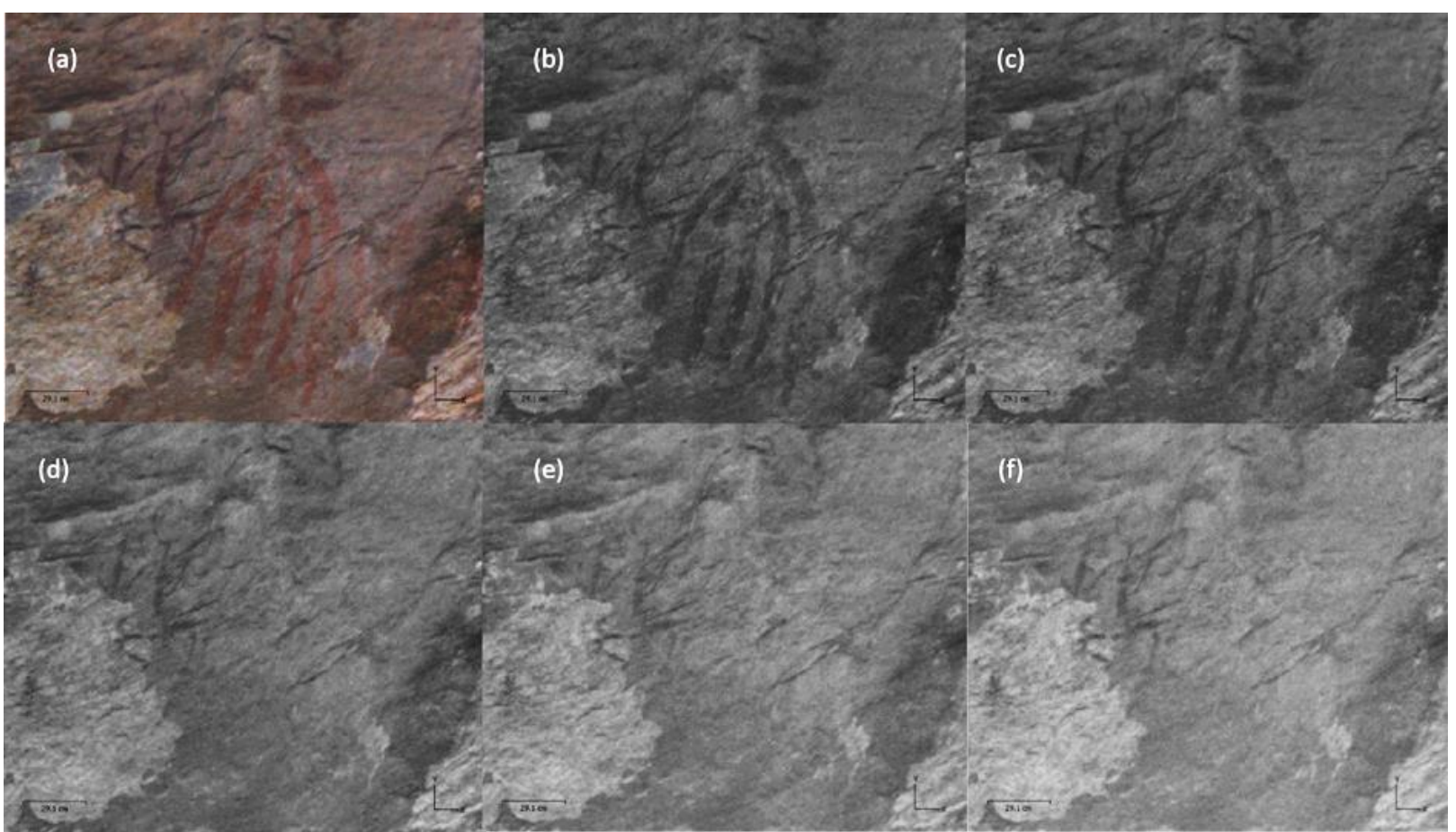

Figure 7: Close view on selected painting based on generated multiband orthophotos: (a)RGB, (b) Blue - 475nm, (c) Green - 560nm, (d) Red - 668nm, (e) Red-Edge - 717nm and (f) NIR - 840nm. 
In the study, control points were extracted from the TLS point cloud due to inability to locate the marker at the tall structure. However, in CH, TLS is not a favorable tool for data acquisition due to the expensive device, although the instrument is becoming smaller and handy to transport into the remote rock art site. Usually, the field data acquisition constrained with a limited budget and the task usually conducted by the volunteers, and to operate the TLS requires the skilled and trained personnel.

Based on the point cloud comparison between multispectral and TLS data shows a similar geometric quality. Therefore, it can be suggested that the lightweight multispectral can use as an alternative to TLS in obtaining rock art paintings data for geometric documentation. This case also applies when data acquisition aims for geometric and radiometric documentation with a single sensor and low-cost budget. However, since the accuracy achieved about $\mathrm{cm}$ level in this project caused by poor planning on control points placement, it is showing the necessary to configure the proper camera network (Barazzetti, 2017; Fraser, 1984; Nocerino et al., 2014) for data acquisition to gain accurate 3D model, especially on the large and tall structure.

From the experiment, using the RedEdge camera limited the production to five bands with the highest wavelength in the camera is $840 \mathrm{~nm}$. Therefore, to get more spectral information, it is recommended to employ a camera system with more wavelength variety, e.g., Mini-MCA (Tetracam, 2017) and MAIA (SAL Engineering, 2017). From the experiments using RedEdge cameras, the produced GSD was $8 \mathrm{~mm} /$ pixels at a circa $10 \mathrm{~m}$ distance of observation. It indicates the camera can provide a sub-cm level for geometric documentation, with proper planning of camera network configuration for data acquisition, performed.

\section{ACKNOWLEDGEMENTS}

The corresponding author would like to thank Universiti Teknologi MARA and the Ministry of Higher Education of Malaysia for financial support under SLAB scheme [500-BPD (BKK.14/3/2/3)]. The authors also highly appreciate the Geospatial Imaging \& Information Research Group and the Faculty of Architecture and Build Environment UTM for the research activities under UTM-GUP-Tier1 (Vote 19H69).

\section{REFERENCES}

Barazzetti, L. (2017). NETWORK DESIGN in CLOSE-RANGE PHOTOGRAMMETRY with SHORT BASELINE IMAGES. ISPRS Annals of the Photogrammetry, Remote Sensing and Spatial Information Sciences, 4(2W2), 17-23. https://doi.org/10.5194/isprs-annals-IV-2-W2-17-2017

Barazzetti, L., Remondino, F., \& Scaioni, M. (2012). Automated and Accurate Orientation of Complex Image Sequences. ISPRS International Archives of the Photogrammetry, Remote Sensing and Spatial Information Sciences, XXXVIII-5/(March), 277-284. https://doi.org/10.5194/isprsarchives-XXXVIII-5-W16-2772011

Bay, H., Ess, A., Tuytelaars, T., \& Van Gool, L. (2008). SpeededUp Robust Features (SURF). Computer Vision and Image Understanding, 110(3), 346-359. https://doi.org/10.1016/j.cviu.2007.09.014

Bendicho, V. M. L.-M., Gutiérrez, M. F., \& Pintado, J. O. (2017). Holistic Approaches to the Comprehensive Management of Rock Art in the Digital Age. In M. L. Vincent, V. M. López-Menchero Bendicho, M. Ioannides, \& T. E. Levy (Eds.), Heritage and
Archaeology in the Digital Age: Acquisition, Curation, and Dissemination of Spatial Cultural Heritage Data (pp. 27-47). Cham: Springer International Publishing. https://doi.org/10.1007/978-3-319-65370-9_2

Beraldin, J. a., Picard, M., Bandiera, A., Valzano, V., \& Negro, F. (2011). Best Practices for the 3D Documentation of the Grotta dei Cervi of Porto Badisco, Italy. Proc. of SPIE-IS\&T Electronic Imaging: Three-Dimensional Imaging, Interaction, and Measurement, $\quad$ 7864(January), 1-15. https://doi.org/10.1117/12.871211

Bianco, S., Colombo, A., Gasparini, F., Schettini, R., \& Zuffi, S. (2011). Applications of Spectral Imaging and Reproduction to Cultural Heritage. Digital Imaging for Cultural Heritage Preservation: Analysis, Restoration, and Reconstruction of Ancient Artworks, 183-213.

Brayer, J. M., Walt, H., \& David, B. (1998). Quantitative assessment of rock art recording. In Tracce Online Rock Art Bulletin, 11 .

Cerrillo-cuenca, E., \& Sepúlveda, M. (2015). An assessment of methods for the digital enhancement of rock paintings: The rock art from the precordillera of Arica (Chile) as a case study. Journal of Archaeological Science, 55, 197-208. https://doi.org/10.1016/j.jas.2015.01.006

Cosentino, A. (2015). Multispectral imaging system using 12 interference filters for mapping pigments. Conservar Património. Associação Profissional de ConservadoresRestauradores de Portugal, 21, 25-38. https://doi.org/10.14568/cp2015005

Del Pozo, S., Rodríguez-Gonzálvez, P., Sánchez-Aparicio, L. J., Muñoz-Nieto, A., Hernández-López, D., Felipe-García, B., \& González-Aguilera, D. (2017). Multispectral Imaging in Cultural Heritage Conservation. ISPRS - International Archives of the Photogrammetry, Remote Sensing and Spatial Information Sciences, $\quad$ XLII-2/W5(September), 155-162. https://doi.org/10.5194/isprs-archives-XLII-2-W5-155-2017

Delporte, H. (1994). L'art pariétal Paléolithique. Techniques et méthodes d'étude. Bulletin de La Société Préhistorique Française, 91(91), 100-101.

Domingo, I., Carrion, B., Blanco, S., \& Lerma, J. L. (2015). Evaluating conventional and advanced visible image enhancement solutions to produce digital tracings at el Carche rock art shelter. Digital Applications in Archaeology and

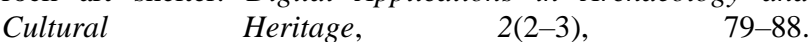
https://doi.org/10.1016/j.daach.2015.01.001

Domingo, I., Villaverde, V., López-Montalvo, E., Lerma, J. L., \& Cabrelles, M. (2013). Latest developments in rock art recording: Towards an integral documentation of Levantine rock art sites combining 2D and 3D recording techniques. Journal of Archaeological Science, 40(4), 1879-1889. https://doi.org/10.1016/j.jas.2012.11.024

Fraser, C. S. (1984). Network Design Considerations for NonTopographic Photogrammetry. Photogrammetric Engineering \& Remote Sensing, 50(8), 1115-1126.

Fredlund, G., \& Sundstrom, L. (2007). Digital infra-red photography for recording painted rock art. Antiquity, 81(313), 733-742. https://doi.org/10.1017/S0003598X00095697

Georgopoulos, A., \& Stathopoulou, E. K. (2017). Data Acquisition for 3D Geometric Recording: State of the Art and Recent Innovations. In M. L. Vincent, V. M. López-Menchero Bendicho, M. Ioannides, \& T. E. Levy (Eds.), Heritage and 
Archaeology in the Digital Age: Acquisition, Curation, and Dissemination of Spatial Cultural Heritage Data (pp. 1-26). Cham: Springer International Publishing. https://doi.org/10.1007/978-3-319-65370-9_1

James, M. R. R., Robson, S., D'Oleire-Oltmanns, S., \& Niethammer, U. (2017). Optimising UAV topographic surveys processed with structure-from-motion: Ground control quality, quantity and bundle adjustment. Geomorphology, 280, 51-66. https://doi.org/10.1016/j.geomorph.2016.11.021

Lerma, J. L., \& Muir, C. (2014). Evaluating the 3D documentation of an early Christian upright stone with carvings from Scotland with multiples images. Journal of Archaeological Science, $46(1)$, https://doi.org/10.1016/j.jas.2014.02.026

Lerma, J. L., Navarro, S., Seguí, A. E., \& Cabrelles, M. (2014). Range-based versus automated markerless image-based techniques for rock art documentation. Photogrammetric Record, 29(145), 30-48. https://doi.org/10.1111/phor.12054

López-Montalvo, E., \& Sanz, I. D. (2005). Nuevas tecnologías y restitución bidimensional de los paneles levantinos: primeros resultados y valoración crítica del método. In Actas del III Congreso del Neolítico en la Península Ibérica: Santander, 5 a 8 de octubre de 2003 (pp. 719-728). Servicio de Publicaciones.

Lowe, D. G. (2004). Distinctive image features from scaleinvariant keypoints. International Journal of Computer Vision, 60(2), 91-110. https://doi.org/10.1023/B:VISI.0000029664.99615.94

Luhmann, T., Fraser, C. S., \& Maas, H. G. (2016). Sensor modelling and camera calibration for close-range photogrammetry. ISPRS Journal of Photogrammetry and Remote Sensing, $\quad 115,37-46$ https://doi.org/10.1016/j.isprsjprs.2015.10.006

Nocerino, E., Menna, F., \& Remondino, F. (2014). Accuracy of typical photogrammetric networks in cultural heritage 3D modeling projects. International Archives of the Photogrammetry, Remote Sensing and Spatial Information Sciences - ISPRS Archives, 40(5), 465-472. https://doi.org/10.5194/isprsarchives-XL-5-465-2014

Pamart, A., Guillon, O., Faraci, S., Gattet, E., Genevois, M., Vallet, J. M., \& De Luca, L. (2017). Multispectral Photogrammetric Data Acquisition and Processing Forwall Paintings Studies. ISPRS - International Archives of the Photogrammetry, Remote Sensing and Spatial Information Sciences, XLII-2/W3(March), 559-566. https://doi.org/10.5194/isprs-archives-XLII-2-W3-559-2017

Remondino, F., \& Fraser, C. S. (2006). Digital camera calibration methods: Considerations and comparisons. International Archives of Photogrammetry and Remote Sensing, 36(5), 266272.

Robson, S., MacDonald, L., Kyle, S., \& Shortis, M. (2014). Multispectral calibration to enhance the metrology performance of C-mount camera systems. International Archives of the Photogrammetry, Remote Sensing and Spatial Information Sciences - ISPRS Archives, 40(5), 517-521. https://doi.org/10.5194/isprsarchives-XL-5-517-2014

SAL Engineering. (2017). MAIA - The multispectral camera. Retrieved November 15, 2017, from http://www.spectralcam.com/maia-tech/

Sanz, I. D. (2014). Rock Art Recording Methods: From Traditional to Digital. In C. Smith (Ed.), Encyclopedia of Global
Archaeology (pp. 6351-6357). New York, NY: Springer New York. https://doi.org/10.1007/978-1-4419-0465-2_1277

Skoog, B., Helmholz, P., \& Belton, D. (2016). Multispectral analysis of indigenous rock art using terrestrial laser scanning. International Archives of the Photogrammetry, Remote Sensing and Spatial Information Sciences - ISPRS Archives, 41(July), 405-412. https://doi.org/10.5194/isprsarchives-XLI-B5-4052016

Tan, N. H., \& Chia, S. (2012). Revisiting the Rock Art at Gua. Crossing Borders: Selected Papers from the 13th International Conference of the European Association of Southeast Asian Archaeologists, Volume 1. Retrieved from $\mathrm{http} / / /$ nuspress.nus.edu.sg/products/crossingborders? variant $=1245109056$

Tetracam. (2017). Mini-MCA. Retrieved November 15, 2017 from http://www.tetracam.com/Products-Mini_MCA.htm

Verhoeven, G. (2016). Basics of Photography for Cultural Heritage Imaging. In $3 D$ Recording, Documentation and Management of Cultural Heritage (pp. 127-251). 